\title{
Website-Based Data Processing for Pregnant Women with the "Sejiwa Dengan Jempol" Innovation Program at the Jabon Health Center
}

\section{Pengolahan Data Ibu Hamil dengan Program Inovasi "Sejiwa Dengan Jempol” di Puskesmas Jabon Berbasis Website}

\author{
Muhammad Fajar Alfian ${ }^{1}$, Ade Eviyanti ${ }^{2}$ \\ $\left\{161080200014 @\right.$ umsida.ac.id ${ }^{1}$, adeeviyanti@umsida.ac.id $\left.{ }^{2}\right\}$
}

Program Studi Informatika, Fakultas Sains dan Teknologi, Universitas Muhammadiyah Sidoarjo, Indonesia

\begin{abstract}
For pregnant women, patient data is very important for the puskesmas, the patient data as a reference for each pregnancy consultation. such information regarding pregnancy data must be designed in a way that makes it easier to find patient data during pregnancy consultations for specific purposes. sejiwa information system, which is a system that can provide information during pregnancy consultation, nutrition for mothers and children in an agency company. the sejiwa information system is expected to make it easier for the community when pregnancy occurs and does not experience stunting, one of which is by presenting complete patient information and regarding the ongoing sejiwa with jempol innovation program at the jabon health center so that it can be reviewed at any time.
\end{abstract}

Keywords - Information system; consultation; pregnancy; patients; psychiatric information systems

\begin{abstract}
Abstrak. Pada ibu hamil data pasien sangat penting bagi pihak puskesmas data pasien tersebut sebagai acuan untuk masa setiap konsultasi kehamilan. Infomasi mengenai kehamilan data tersebut harus dirancang secara segnifikan upaya memudahkan pencarian data pasien pada saat konsultasi masa kehamilan untuk keperluan tertentu. Sistem Informasi Sejiwa yaitu sistem dapat memberi informasi pada masa konsultasi kehamilan, pemberian gizi ibu dan aanak pada suatu perusahaan instansi. Sistem informasi Sejiwa, diharapkan dapat memepermudah masyarakat pada saat kehamilan terjadi dan tidak mengalami stunting, salah satunya seperti menyajikan informasi lengkap pasien serta mengenai berlangsungnya program inovasi Sejiwa dengan Jempol di puskesmas Jabon guna untuk dapat ditinjau sewaktu-waktu.
\end{abstract}

Kata Kunci - Sistem informasi; Konsultasi; Kehamilan; Pasien; Sistem Informasi Sejiwa

\section{Pendahuluan}

Untuk ibu hamil yang lupa akan pentingnya membawa buku Kesehatan Ibu dan Anak, terkadang ibu hamil tidak mengetahui apa maksud buku tersebut sebagai alat control rutin setiap konsultasi, terkadang buku KIA yang dibawa juga hilang.[1].

Sistem informasi peringatan dini risiko kehamilan dapat digunakan untuk wanita hamil dan deteksi penyedia layanan kesehatan dalam sistem informasi peringatan awal pada kerentanan dari kehamilan guna sebagai melayani penyedia layanan dalam ekspansi objektivitas [2].

Sitem informasi kesehatan pada ibu hamil dan anak pada input system pada dasarnya terdiri sistem pendataan pasien baru, rencana persalinan, catatan kelahiran, catatan pemeriksaan anak, catatan imunisasi, dan catatan pemberian vitamin A [3].

Penerapan manejemen penerapan pelaksaan dalam bentuk forum pertemuan lintas sektor menyepakati dibentuknya program inovasi SEJIWA dengan JEMPOL (Selamatkan Jiwa Wanita dan Anak dengan penandaan Jempol). Program ini diawali dengan membuat perjanjian kerjasama antara Puskesmas Jabon dengan bapak Camat Jabon. Kemudian dilanjutkan launching program Inovasi Sejiwa Jempol dengan menghadirkan seluruh kepala desa, Tim penggerak PKK (Pemberdayaan Kesejahtraan Keluarga) serta melibatkan kepala desa, tokoh agama, tokoh masyarakat, dan kader kesehatan desa Saat ini program inovasi SEJIWA dengan JEMPOL mensosialisasikan program tersebut menggunakan media sosial berupua Youtube Informasi yang disampaikan berupa tentang 8 kriteria diantaranya (Pemeriksakan kehamilan pertama dengan usia kehamilan $<12$ minggu, Dilakukan secara terpadu/ Interprofesi, Memiliki calon pendonor darah, Ikut kelas ibu hamil, ANC (Anttenatal Care atau Perencanaan Kehamilan) yang telah dilakukan minimal 4 kali, Bukan termasuk kriteria 4 Terlalu: 1.) Terlalu tua, 2.) Terlalu Muda hamil, 3.) Terlalu banyak anak, 4.) Jarak persalinan yang Terlalu dekat, Telah memiliki kartu anggota P4K (Perencanaan Persalinan dan Pencegahan Komplikasi), Telah memiliki asuransi kesehatan BPJS [4].

Dengan adanya program inovasi SEJIWA dengan JEMPOL sebelumnya masih menggunakan media informasi youtube, menemukan factor resiko kesehatan lain pada wanita yang seharusnya masih bisa di cegah sebelum terjadi kehamilan [5]. Oleh karena itu sebagai tindak lanjut untuk mempermudah akses kepada masyarakat, Pada pemeriksaan pertama baik di kelas ibu hamil maupun di Puskesmas, ibu hamil akan mendapatkan buku KIA dan ceklist penandaan 
Procedia of Engineering and Life Science Vol. 1. No. 2 Juni 2021

Seminar Nasional \& Call Paper Fakultas Sains dan Teknologi (SENASAINS 2nd)

Universitas Muhammadiyah Sidoarjo

JEMPOL[6]. Dengan adanya permasalahan sebagai penulis bermaksud untuk membuat sistem informasi SEJIWA Dengan JEMPOL berbasis website sehingga masyarakat dapat mendapatkan informasi yang lebih lengkap mengenai kehamilan [7].

\section{A. Metode perancangan sistem}

\section{METODE}

Dalam perancangan sistem mengawasi kemajuan kegiatan pemesanan dan pemasaran guna pengambilan keputusan strategi pemasaran menggunakan pendekatan model waterfall, Waterfall adalah Pendekatan paling awal SDLC digunakan untuk dalam perangkat lunak waterfall yaitu sebagai siklus hidup dengan berurutan linear, dalam setiap fase pengembangan dimulai pada tahap sebelumnya berakhir [8].

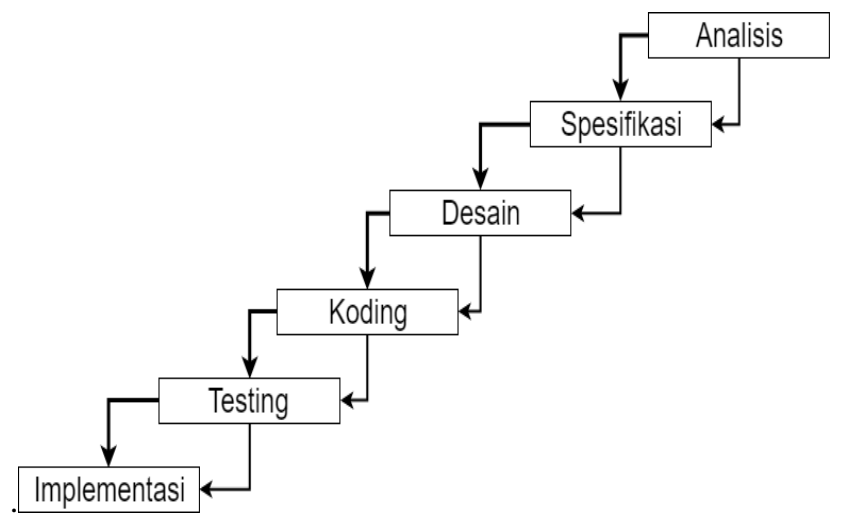

Gambar 1. Metode Waterfall

\section{B. Perancangan flowchart}

Pada flowchart ini menunjukan alur proses sistem jika digunakan ingin masuk kedalam sistem

Flowchart user

Pada flowchart ini menjelaskan tentang alur proses jika user masuk ke system harus terkonfirmasi akun ke admin agar dapat login ke system dan sebagai pasien, penguna dapat melihat informasi kriteria pada masa kehamilan, melihat data kriteria pada informasi Sejiwa dengan Jempol, dan juga lebih menariknya outputnya akan pasien mendapatkan penghargaan atau reward untuk pada masa lahiran dari puskesmas [9].

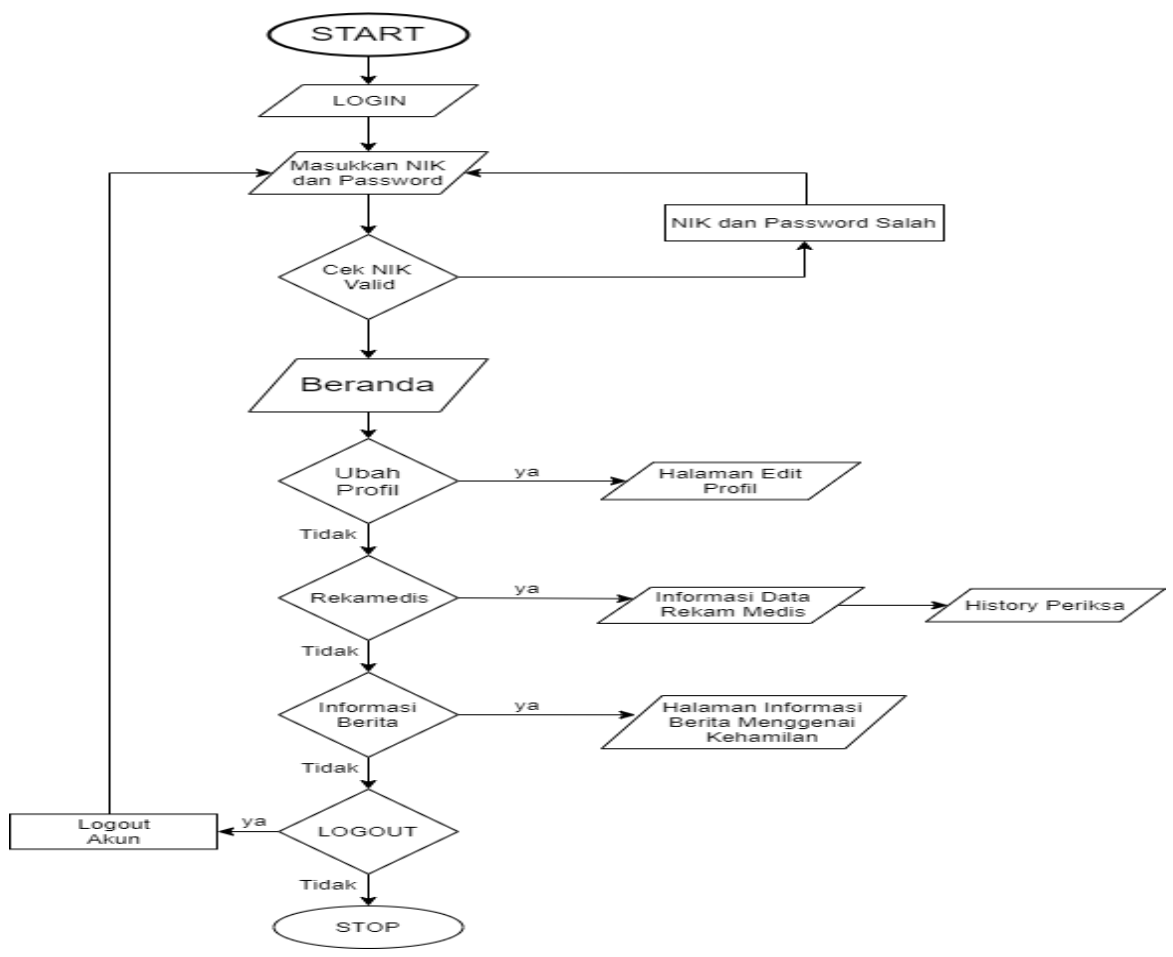

Gambar 2. Flowchart User 
Procedia of Engineering and Life Science Vol. 1. No. 2 Juni 2021

Seminar Nasional \& Call Paper Fakultas Sains dan Teknologi (SENASAINS $2^{\text {nd }}$ )

Universitas Muhammadiyah Sidoarjo

Flowchart admin

Alur Flowchart admin ini yang mengelola sistem dengan login mengisi username dan password masuk halaman menu yang akan bertugas mengelola data konsukltasi, mengelola berita dan juga mengelola akun user.

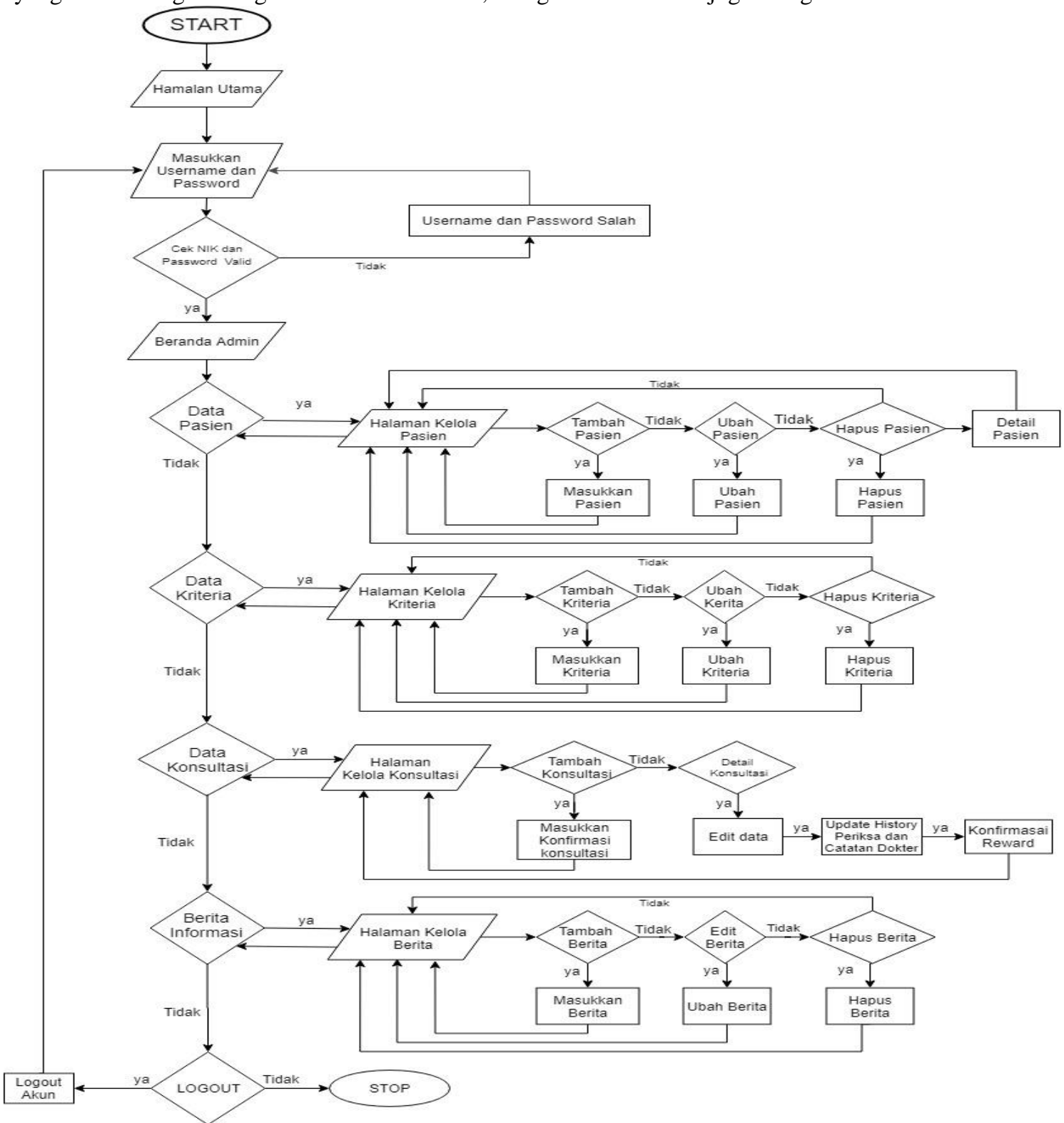

Gambar 3. Flowchart Admin

Use case diagram sistem

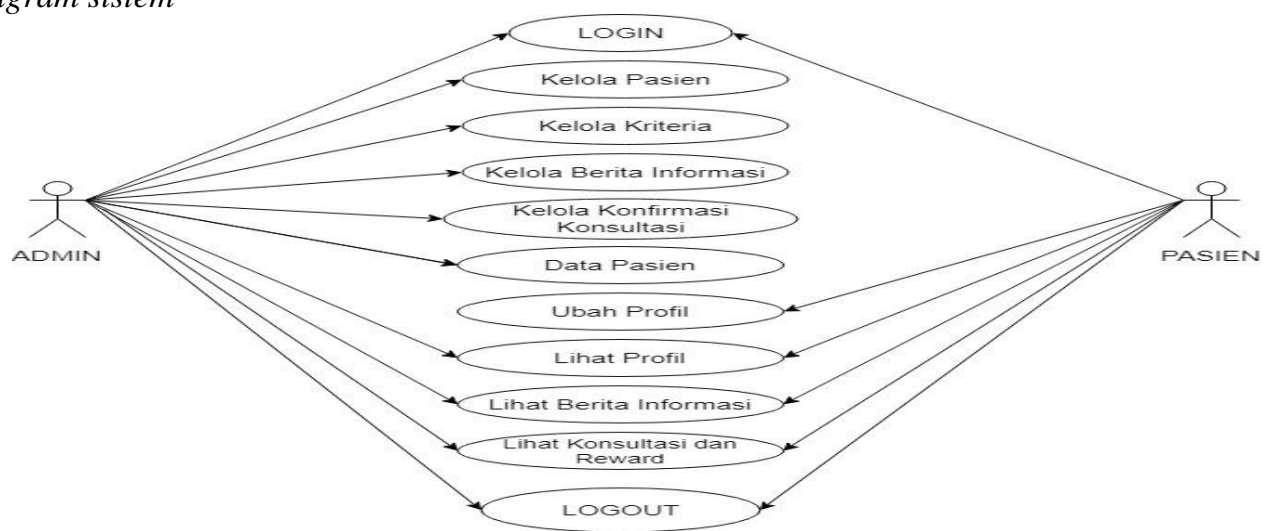

Gambar 4. Use Case 
Procedia of Engineering and Life Science Vol. 1. No. 2 Juni 2021

Seminar Nasional \& Call Paper Fakultas Sains dan Teknologi (SENASAINS 2nd)

Universitas Muhammadiyah Sidoarjo

Admin Puskesmas disini bertugas sebagai mengelola data pasien dan juga mengelola data kriteria dalam mengelola data dengan tugas admin yaitu membutuhkan melihat data, mengubah data, menghapus data, dan membuat data. Peran pertama admin biasanya menambahkan data pasien dengan megelola pasien, mengelola kriteria. Untuk peran utama pada pasien biasanya melihat informasi sistem, melihat data sudah dikonfirmasi, serta edit profil, maupun menganti password [10].

\section{Hasil dan Pembahasan}

\section{A. Pembahasan}

\section{Halaman Login}

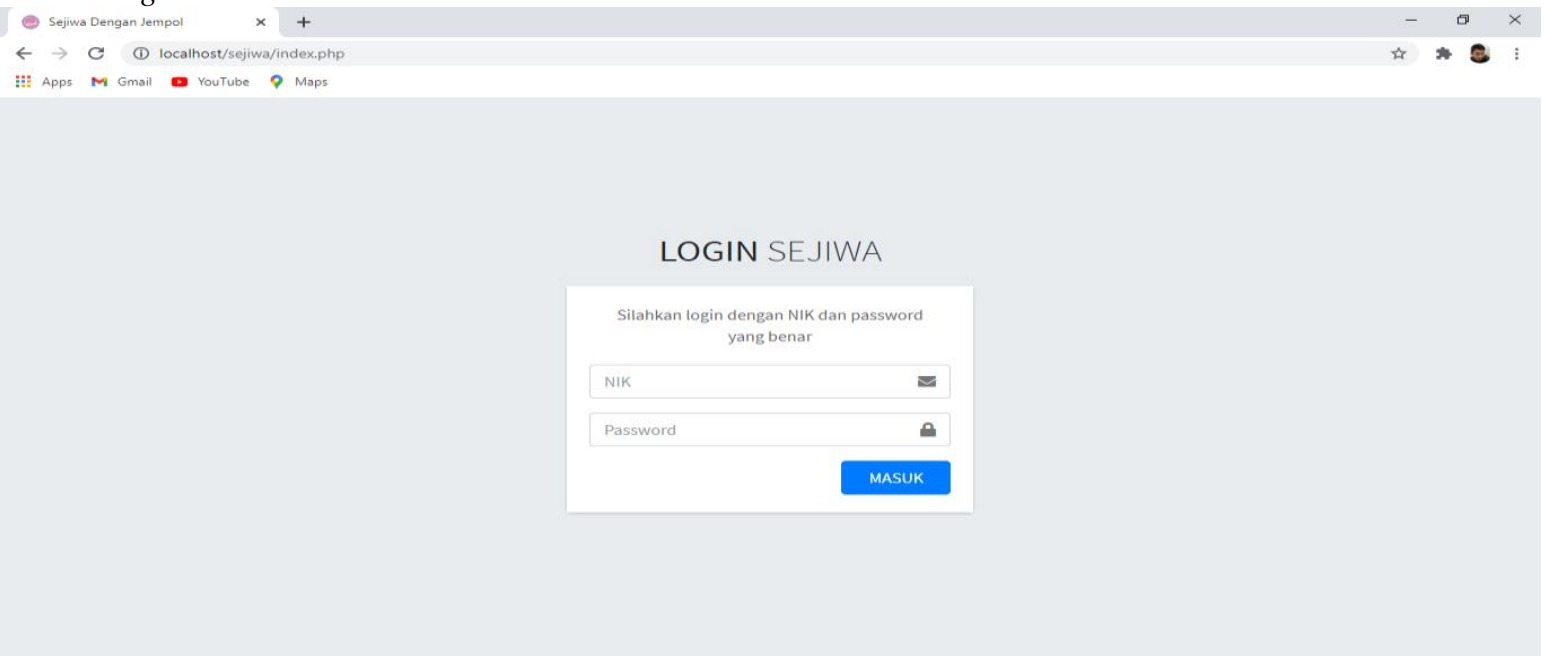

Gambar 5. Halaman Login

Pada halaman utama login pasien dapat memasukkan NIK (Nomer Induk Keluarga) dan password yang dapat diakses atau sudah terdaftar, jika pasien login harus memiliki NIK dan password yang benar yang telah terdaftar sebelumnya dimintai KK (Kartu Keluarga) oleh admin sebagai registrasi data.

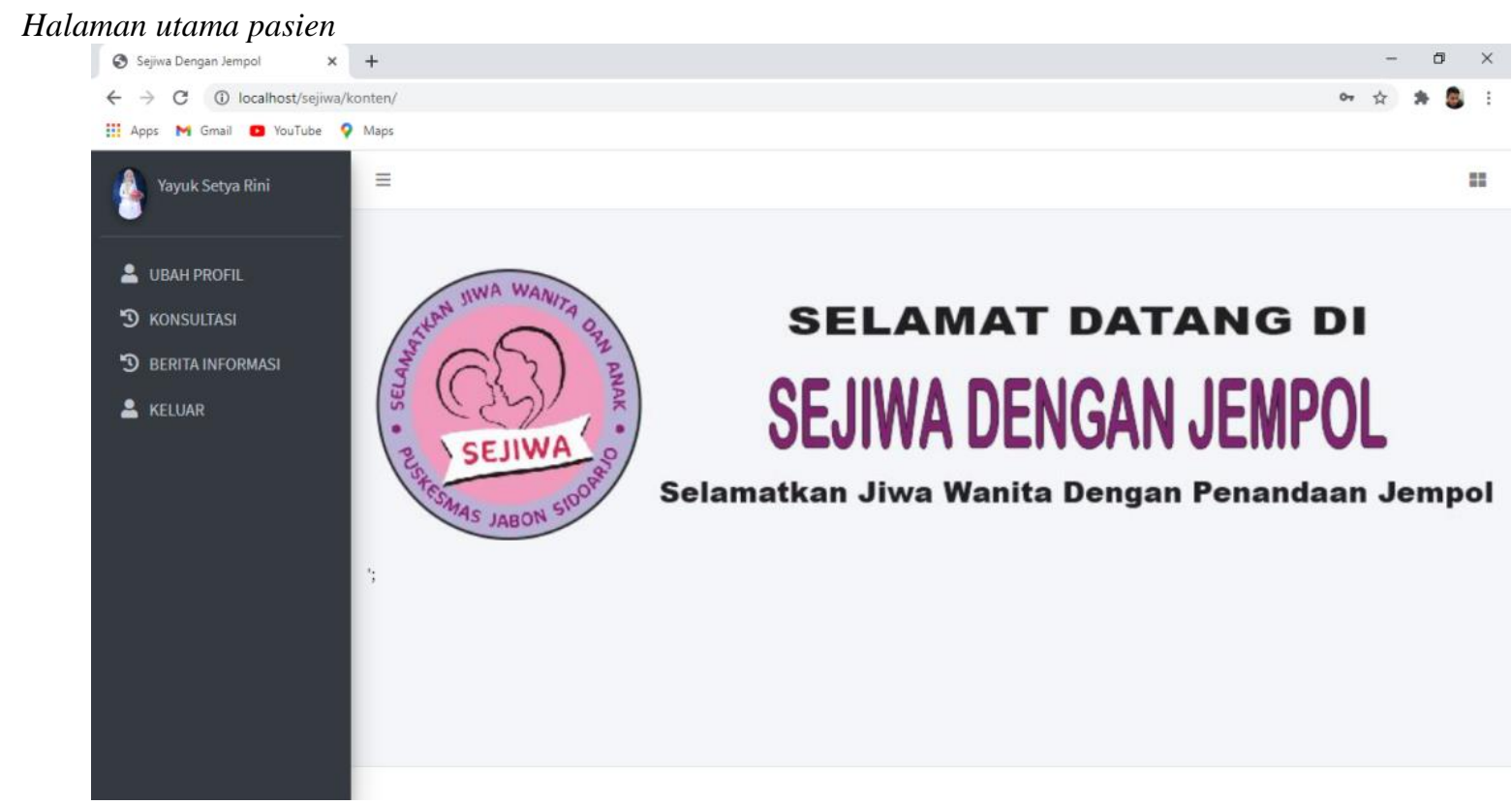

Gambar 6. Halaman Utama Pasien

Pada halaman utama terdapat menu Ubah Profil, Konsultasi, Berita Info dan Keluar, pasien disambut dengan Selamat Datang di Sejiwa dengan Jempol di Puskesmas Jabon yang dapat diakses untuk semua pengunjung yang sudah login terlebih dahulu. Jika ingin login pasien dapat memasukkan NIK dan Password yang benar yang telah terdaftar sebagai program Sejiwa Dengan Jempol di Puskesmas Jabon. 
Procedia of Engineering and Life Science Vol. 1. No. 2 Juni 2021

Seminar Nasional \& Call Paper Fakultas Sains dan Teknologi (SENASAINS $2^{\text {nd }}$ )

Universitas Muhammadiyah Sidoarjo

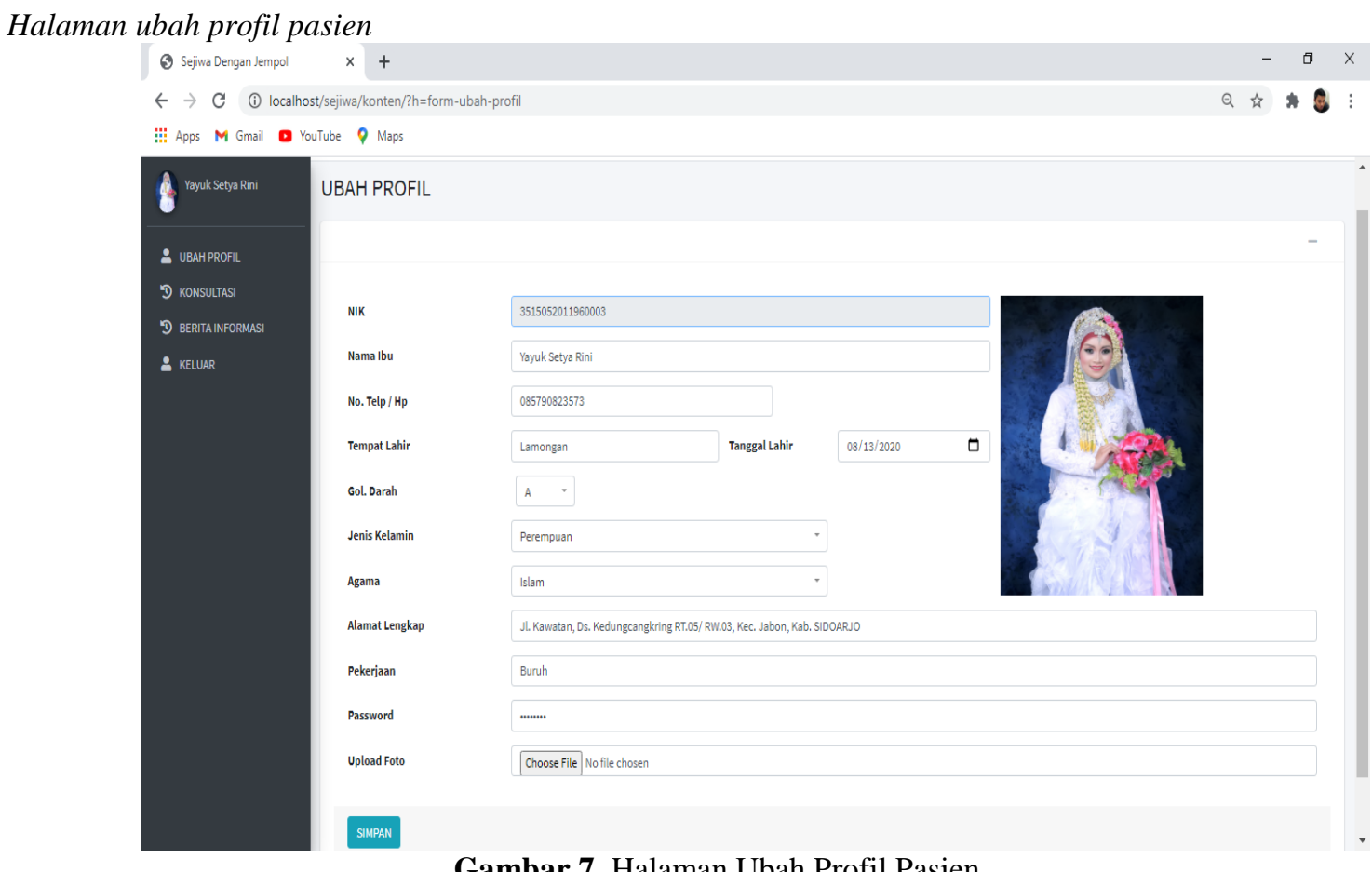

Pada menu halaman ubah profil pasien terdapat mengubah biodata pasien apabila terjadi kekeliruan dalam memasukan informasi yang dapat dituju dalam mencatat biodata disini pasien dapat mengubah No.Rekamedis, Username, Password, Alamat Lengkap, Usia, Jenis Kelamin dan Pekerjaan kemudian klik Simpan data.

Halaman konsultasi pasien

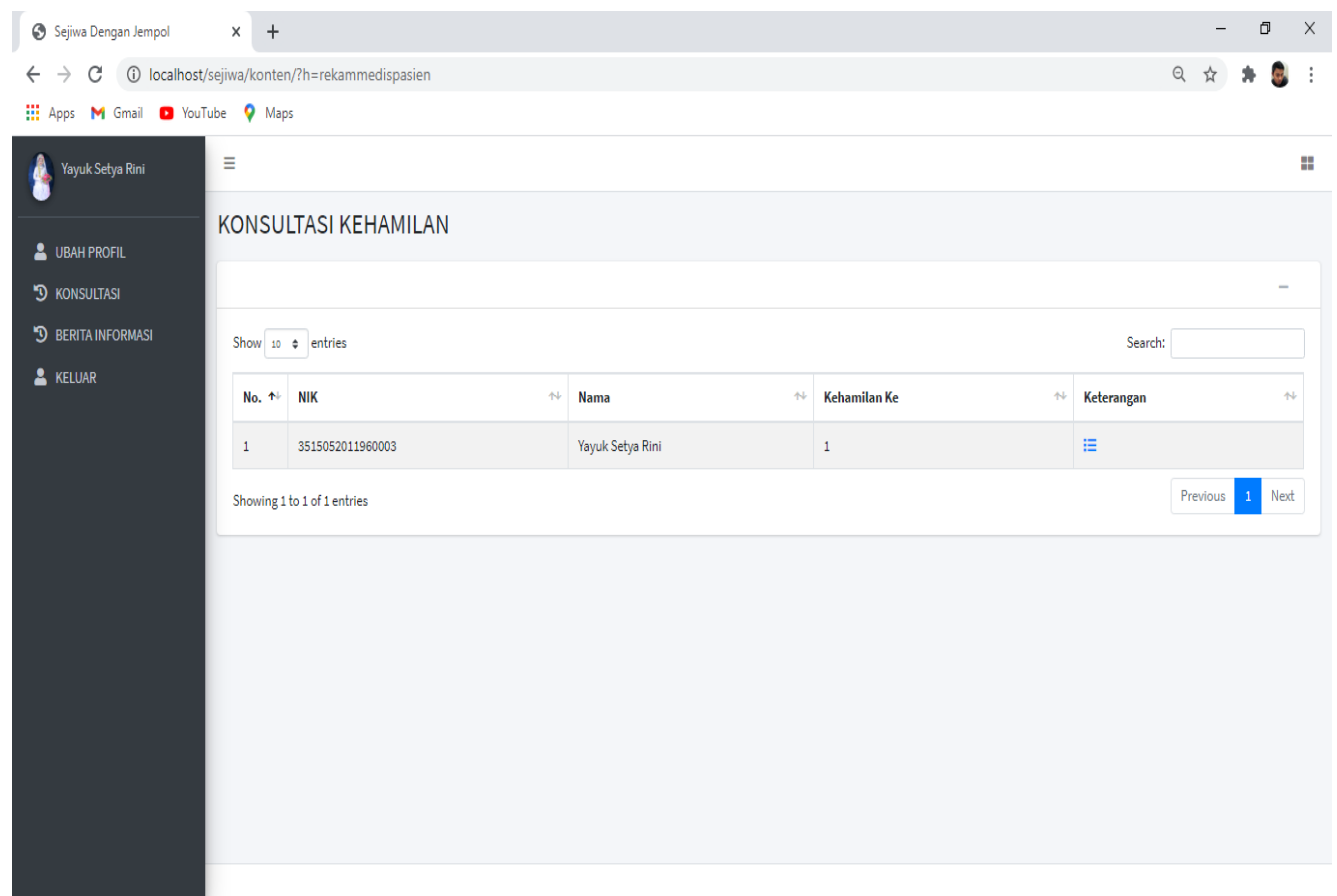

Gambar 8. Halaman Konsultasi Pasien

Pada halaman konsultasi pasien dapat mengetahui konsultasi kehamilan baik sudah maupun belum memenuhi 8 kriteria dan juga terdapat sebagai reward/penghargaan jika sudah memenuhi 8 kriteria yang sudah di tentukan oleh pihak admin dalam memenuhi program novasi Sejiwa Dengan Jempol di Puskesmas Jabon. 
Procedia of Engineering and Life Science Vol. 1. No. 2 Juni 2021

Seminar Nasional \& Call Paper Fakultas Sains dan Teknologi (SENASAINS $2^{\text {nd }}$ )

Universitas Muhammadiyah Sidoarjo

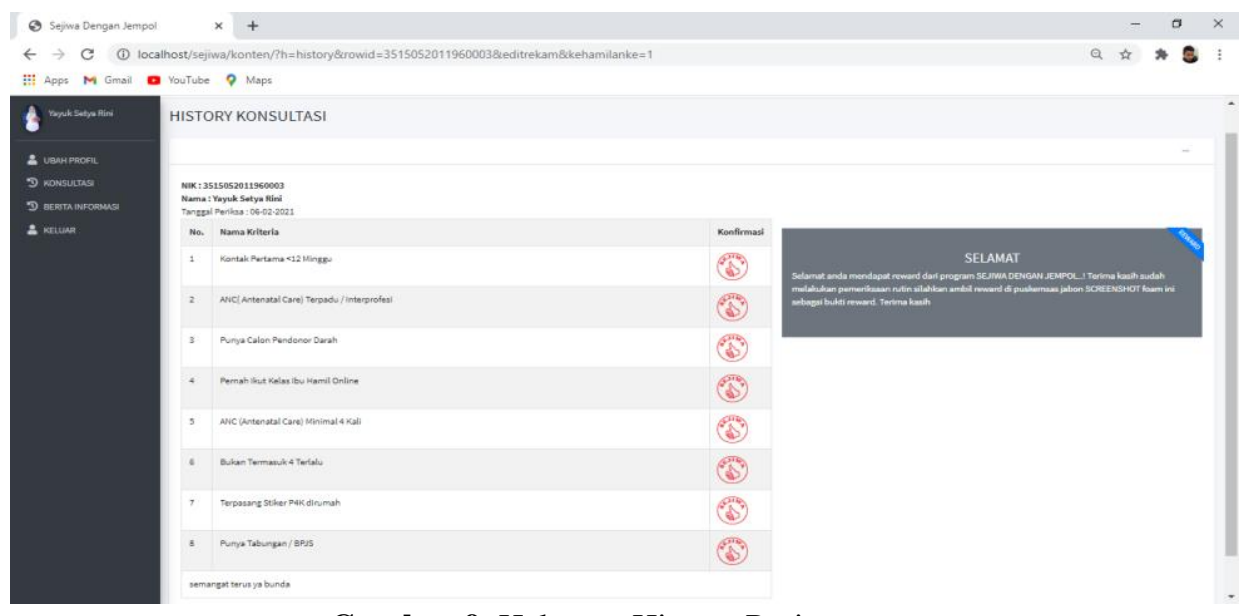

Gambar 9. Halaman History Pasien

Pada Halaman history pasien yaitu mengetahui konsultasi kehamilan terkait 8 kriteria dan juga terdapat sebagai reward/penghargaan jika sudah memenuhi 8 kriteria yang sudah di tentukan oleh pihak admin Sejiwa.

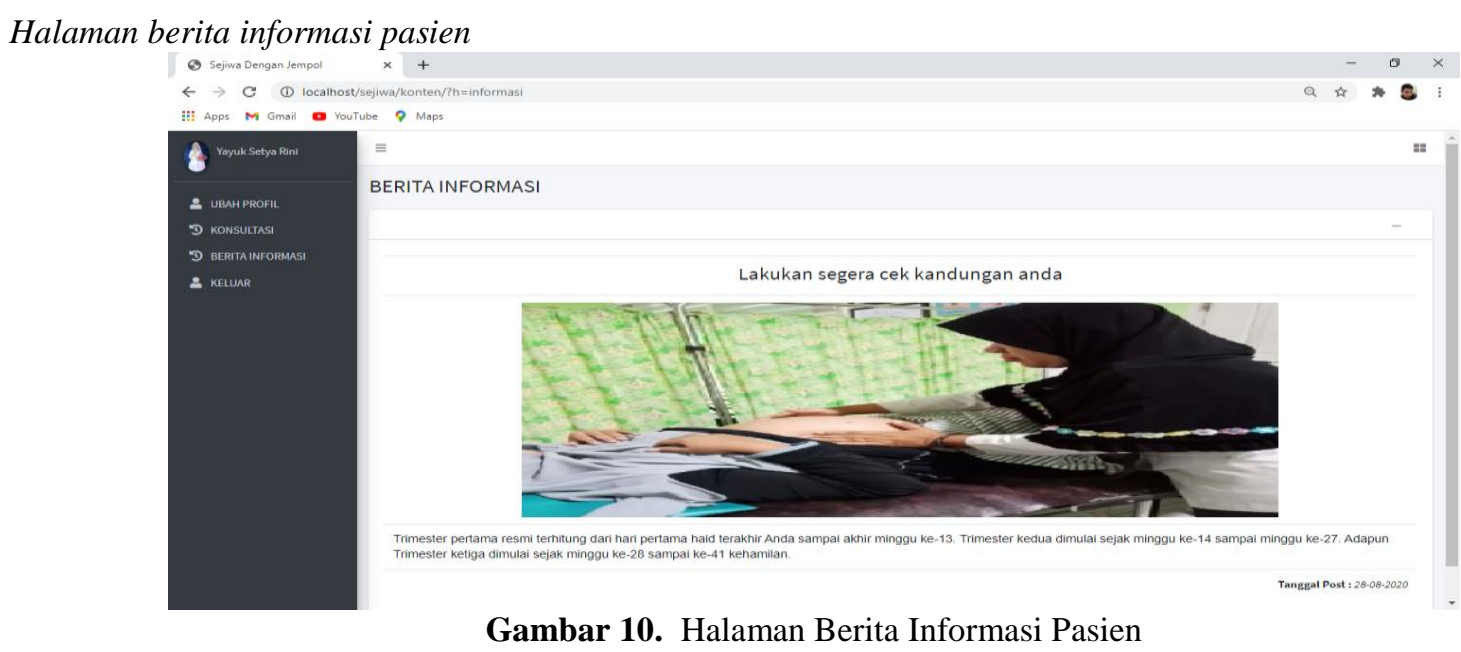

Pada halaman berita informasi pasien dapat mengetahui program kehamilan yang diperlukan serta bagaimana dapat menjaga kesehatan ibu dan anak pada pasca masa kehamilan berlanjut agar anak dapat terlahir dengan sehat dan normal.

\section{B. Pengujian sistem}

Untuk proses ini akan melakukan pengujian system dengan supayaa dapat menemukan kekurangan atau kesalahan sistem pada perangkat lunak atau sistem yang diuji dapat mengetahui apakah sistem ini sudah memenuhi target yang diinginkan sesua yaitu tujuan perancangan sebelumnya.

Pengujian fungsional

Dalam pengujian sistem ini peneliti berharap tidak ada kesalahan atau error dalam menjalankan sistem.

Tabel 1. Pengujian Website Admin

\begin{tabular}{llc}
\hline \multicolumn{1}{c}{ Uji Fitur } & \multicolumn{1}{c}{ Detali Pengujian } & Jenis Pengujian \\
\hline Login & Isi form login admin & Black Box \\
\hline Beranda & Menampilak form admin & Black Box \\
\hline Pasien & Mengelola data pasien & Black Box \\
\hline Kritreria & Mengelola data kriteria & Black Box \\
\hline Konsultasi & Mengelola data konsultasi & Black Box \\
\hline History Konfirmasi Konsultasi & Menampilkan laporan dan data konfirmasi konsultasi & Black Box \\
\hline Berita Informasi & Mengelola data berita informasi & Black Box \\
\hline
\end{tabular}


Procedia of Engineering and Life Science Vol. 1. No. 2 Juni 2021

Seminar Nasional \& Call Paper Fakultas Sains dan Teknologi (SENASAINS 2nd)

Universitas Muhammadiyah Sidoarjo

Tabel 2. Pengujian Website Pengguna

\begin{tabular}{lll}
\hline \multicolumn{1}{c}{ Uji Fitur } & \multicolumn{1}{c}{ Detali Pengujian } & Jenis Pengujian \\
\hline Akses tiap tab & Melakukan akses tiap tab & Black Box \\
\hline Tab Ubah Profil & Informasi produk & Black Box \\
\hline Tab Konsultasi & Menampilkan informasi kosultasi & Black Box \\
\hline History Konsultasi & Menampilkan informasi kosultasi dan reward & Black Box \\
\hline Tab Berita Informasi & Menampilakn berita informasi kehamilan & Black Box \\
\hline
\end{tabular}

\section{KESIMPULAN}

Berdasarkan hasil pengujian dan juga analisa yang telah dilakukan maka dapat disimpulkan bahwa sistem sudah sesuai dengan perancangan yang diinginkan oleh pihak instansi dan juga masyarakat jabon. Sistem informasi ini dapat mempermudah petugas puskesmas jabon dalam pengolahan data dan dalam memenuhi 8 kriteria ibu hamil. Sistem informasi sudah memberikan akses untuk pasien untuk melihat informasi masa konsultasi dan memenuhi 8 kriteria Sejiwa Dengan Jempol. Sistem informasi lebih efisien dan akurat dalam memberikan informasi 8 kriteria Sejiwa Dengan Jempol.

\section{REFERENSI}

[1] L Widagdo, BT Husodo, (2009), Pemanfaatan Buku Kia Oleh Kader Posyandu Studi Pada Kader Posyandu Di Wilayah Kerja Puskesmas Kedungadem Kabupaten Bojonegoro, Makara, kesehatan.

[2] Delimayanti, M. K, (2007), Perancangan Dan Analisis Perangkat Lunak Berbasis Web. Management.

[3] Saraswati, E, (1998), Resiko Ibu Hamil Kurang Energi Kronis (KEK) dan Anemia untuk melahirkan Bayi dengan Berat Badan Lahir Rendah (BBLR).

[4] I Retnowati, ADAAK Estu, (2010), Hubungan Penerapan Program Perencanaan Persalinan Dan Pencegahan Komplikasi (P4k) Oleh Ibu Hamil Dengan Upaya Pencegahan Komplikasi Kehamilan Di Puskesmas Sidorejo Kidul Salatiga, Jurnal Kebidanan.

[5] Sarimawar, D., dkk, (1991), Faktor Resiko yang Mempengaruhi Anemia Kehamilan. Buletin Penelitian Kesehatan. Jakarta,.

[6] N Elly, (2003), Pemanfaatan buku KIA sebagai materi penyuluhan dalam pelayanan antenatal oleh bidan Puskesmas di Kota Bengkulu, Jurnal Manajemen Pelayanan Kesehatan, FK-UGM, Yogyakarta,.

[7] Z. Lubis, Status Gizi Ibu Hamil Serta Pengaruhnya Terhadap Bayi yang Dilahirkan, Tersedia di Zulhaida@ telkom. net, (2003).

[8] Jogiyanto, (2001), System Development Life Cycle.

[9] N. Chapin, (2003), Encyclopedia of Computer Science.

[10] Doug Rosenberg, Kendall Scott, (2001), Applying Use Case Driven Object Modeling With UML. 